\title{
Characterizing of Air Pollution in Tehran: Comparison of Two Air Quality Indices
}

\author{
Saeed Motesaddi ${ }^{\mathrm{a}}$, Yalda Hashempour ${ }^{\mathrm{b}}{ }^{*}$, Parviz Nowrouz ${ }^{\mathrm{b}}$ \\ ${ }^{a}$ Department of Environmental Health Engineering, School of Public Health, Shahid Beheshti University of Medical Sciences, Tehran, Iran. \\ ${ }^{b}$ Department of Environmental Health Engineering, School of Public Health, student's research committee, Shahid Beheshti University of Medical \\ Sciences, Tehran, Iran.
}

Received 20 August 2017; Accepted 28 September 2017

\begin{abstract}
Multi-pollutant air pollution dramatically occurs in wide range of regions across Tehran. Air quality index (AQI) is applied worldwide to inform the public about levels of air pollution and related to health risks. Assessing air pollution, and transferring information about its possible adverse health effects, may encourage population and policy makers to reduce activities that increase pollution levels. In this study the Air quality index (AQI), Aggregate Air quality index (AAQI), and a relative index of variability (VR) were obtained for the data in order to better investigate air pollution conditions for the whole areas of a city of Tehran, aim at warning the people of short-term health impact. The proposed index of variability does add precious information to the aggregate AQI, as it can demonstrate whether the value assumed by the AQI is influenced by one or more pollutants. The two indices are together used on simulated data and consider different possible scenarios. In addition, Applications to real air pollution data are reported. Before applying the two indices, the effects of different standardizations on data are evaluated from a theoretical point of view.
\end{abstract}

Keywords: Air Quality Index (AQI); Tehran; Indices; Variability Index.

\section{Introduction}

Clean air is regarded as one of the most significant requirements for human health. Over 50 years, air pollution and its impact on human health are a concern for the World Health Organization (WHO). For this reason guideline with the aim to protect public health from the adverse effects of air pollutants has developed [1,2].

Nowadays, the majority of the capital cities in the world are being faced with air pollution problem [3]. Tehran city, as one of those capital cities, has been experiencing serious air pollution problems in recent decades as a result of uncontrolled population growth, immigration, and not paying attention to environmental issues. A large number of studies have demonstrated relations between air pollution and a verity of health effects $[4,5]$. The results of these studies have confirmed that air pollution is a serious threat to public health. As a consequence, it is vital to notify the public about the levels of air pollution and related health risks so that people can take measures to keep their health [6, 7].

Air pollution levels are determined by the concentrations of an intricate mixture of air pollutants. Currently, $\mathrm{CO}, \mathrm{O} 3$, NO2, SO2, PM10, and PM2.5 are set as the world's six criteria pollutants in quantifying air pollution levels [1,8]. The concentrations of the pollutants can be different, and their unit concentration health effects are considerably different too. Therefore, it is not easy for the general public to use the concentrations straight to illustrate the levels of air pollution $[9,10]$. Otherwise, general public understands the use of an index ranging from good to unhealthy, and it becomes the

* Corresponding author: yalda.hashempour@yahoo.com

DOI: http://dx.doi.org/10.21859/cej-030911

$>$ This is an open access article under the CC-BY license (https://creativecommons.org/licenses/by/4.0/).

(C) Authors retain all copyrights. 
most popular way to clarify air pollution levels in the vast range of countries and regions. Such indices were firstly developed in early 1970 's, and have been evolving since then [11, 12]. There are various air pollution quality indexes like Air Quality Index (AQI) which is also known as Air Pollution Index (API) [13] or Pollutant Standard Index (PSI) $[4,14]$. Now, AQI is a more sophisticated and widely used approach to communicate the health risk of ambient concentrations by using an air pollution index. The most frequently applied index is the United States Environmental Protection Agency (US EPA) AQI. The AQI sorts from 0 to 500 and is calculated based on the six criteria pollutants $[15,16]$.

For a given day and a given location, a sub-AQI for every pollutant is computed, and the maximum of all the subAQIs is explained as the overall AQI. It points out "unhealthy" air quality when AQI is greater than 100. This method has been criticized, which is mainly because it does not properly signify the combined health effects of exposure to multiple pollutants [17-19].

A few studies have been directed to develop alternative approaches that take our view into account the integrated health effects of several pollutants. Ruggieri and Plaia (2012) compared different standardizations for the air pollutants [1]. Moreover, the evaluation of three air quality indices AQI, AAQI, and HAQI was computed based on data collected in six capital of China by Hu et al. The results show that the AAQI judges the air pollution exposure more efficiently than the US EPA AQI $[8,20]$.

The Environmental Protection Agency of Iran adopted the US EPA AQI approach. No studies have been conducted to examine the differences between the AQI, and AAQI approaches in designating air pollution severities in Tehran, Iran.

In this study, air pollution data collected in Tehran are analyzed. The AQI, AAQI, and a relative index of variability (VR) were obtained for the data. These indices were compared in different years (from March 2007 to March 2014). It allows knowing that one or more pollutants are responsible for the aggregate AQI. Such information could be valuable especially for policy-makers so as to take appropriate intervention measures for the specific pollutant influencing the AQI.

\section{Methods}

\subsection{Study Areas and Data Source}

This cross-sectional study was carried out in Tehran. Tehran is situated in the Northern part of Iran and $34^{\circ}$ and $36^{\circ}$ North latitude and $50^{\circ}$ and $53^{\circ}$ east longitude. The climate is commonly semi-arid; it can be generally defined as mild in the spring and autumn, hot and dry in the summer, and cold and wet in the winter. Because of population density, more developed economy and frequent incidents of air pollution, Tehran is perceived as one of the most polluted cities. Total numbers of pollution measurement stations in the city were 21. Figure 1. shows the locations of the stations. The data utilized in the present study, consist of five main common pollutants $\left(\mathrm{PM}_{10}, \mathrm{CO}, \mathrm{O}_{3}, \mathrm{SO}_{2}\right.$, and $\left.\mathrm{NO}_{2}\right)$ are collected and registered by the Tehran air quality control organization and Tehran air pollution monitoring center over the period from April 2007 to April 2014. Furthermore, $\mathrm{PM}_{2.5}$ measurement is added to the stations since 2010. More importantly, data for January, February, and March in 2009 were not available. The monitoring systems work automatically and have been installed and used based on Environmental Protection Standards to measure the concentration of pollutant. Then the average hourly concentrations of mentioned pollutants in different days in these stations were calculated using Excel software. Based on data collected, two indicators, AQI, and AAQI were studied. The comparison of the indices using data from the 21 stations could provide the right context for overall understanding to identify the characteristics of the air pollution exposures in Tehran with the aim of informing citizens and/or decision-makers about the trend of air pollution. 


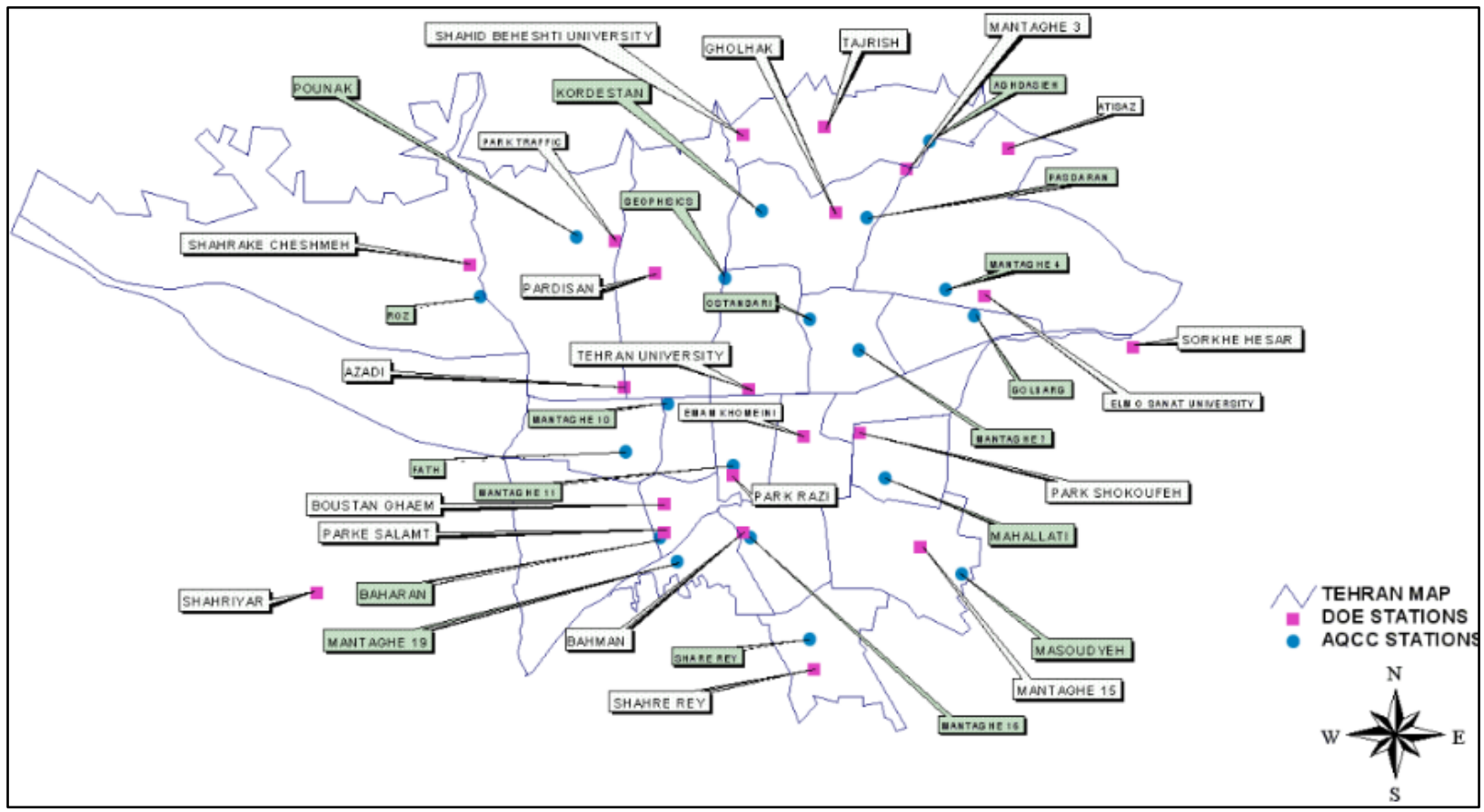

Figure 1. Location of pollution measurement stations in Tehran

\subsection{Air Quality Index}

The air quality index (AQI) for each observed pollutant concentrations is calculated based on Equation 1:

$$
\begin{aligned}
& A Q I_{i}=\frac{\left(A Q I_{i, j}-A Q I_{i, j-1}\right)}{\left(C_{i, j}-C_{i, j-1}\right)} \times\left(C_{i, m}-C_{i, j-1}\right)+A Q I_{i, j-1} j \succ 1 \\
& A Q I_{i}=A Q I_{i, 1} \frac{C i, m}{C_{i, 1}}, j=1
\end{aligned}
$$

Breakpoint concentrations have been defined by EPA on the basis of the NAAQS (National Ambient Air Quality Standards) and as regards of the results of epidemiological studies on the effect of each pollutant on human health (see Table 1) [11].

Table 1. Breakpoint for EPA AQI

\begin{tabular}{ccccccc}
\hline Pollution category & $\mathbf{A Q \mathbf { I } _ { \mathbf { i } }}$ & $\mathbf{P M}_{\mathbf{1 0}}\left(\boldsymbol{\mu \mathbf { g } . \mathbf { m } ^ { \mathbf { 3 } } )}\right.$ & $\mathbf{N O}_{\mathbf{2}}(\mathbf{p p m})$ & $\mathbf{C O}(\mathbf{p p m})$ & $\mathbf{S O}_{2}(\mathbf{p p m})$ & $\mathbf{O}_{\mathbf{3}} \mathbf{8 h}(\mathbf{p p m})$ \\
\hline Hazardous & $401-500$ & $505-604$ & $1.65-2.04$ & $40.5-50.4$ & $0.805-1.004$ & $(1)$ \\
Hazardous & $301-400$ & $425-504$ & $1.25-1.64$ & $30.5-40.4$ & $0.605-0.804$ & $(1)$ \\
Very unhealthy & $201-300$ & $355-424$ & $0.65-1.24$ & $15.5-30.4$ & $0.305-0.604$ & $0.116-0.374$ \\
$\quad$ Unhealthy & $151-150$ & $255-354$ & $0.361-0.64$ & $12.5-15.4$ & $0.225-0.304$ & $0.096-0.115$ \\
Unhealthy for sensitive & $101-150$ & $155-254$ & $0.101-0.36$ & $9.5-12.4$ & $0.145-0.224$ & $0.076-0.095$ \\
$\quad$ groups & $51-100$ & $55-154$ & $0.054-0.1$ & $4.5-0.4$ & $0.035-0.144$ & $0.06-0.075$ \\
Moderate & $0-50$ & $0-54$ & $0-0.053$ & $0.0-4.4$ & $0.0-0.034$ & $0.0-0.059$ \\
Good & & &
\end{tabular}

(1) $8 \mathrm{~h} \mathrm{O}_{3}$ values do not define higher $\mathrm{AQI}_{\mathrm{i}}$ values $(\geqslant 301)$. $\mathrm{AQI}_{\mathrm{i}}$ values of 301 or higher are calculated with $1 \mathrm{~h} \mathrm{O}_{3}$ concentrations.

The overall $\mathrm{AQI}$ is the maximum among the single $\mathrm{AQI}_{\mathrm{is}}$, as shown in Equation 2:

$$
A Q I=\max \left(A Q I_{1}, \mathrm{AQI}_{2}, \ldots, \mathrm{AQI}{ }_{\mathrm{n}}\right), \mathrm{n}=1,2, \ldots, \mathrm{n}
$$

After the standardizing transformation, a value on a scale between 0 and 500 is gained for each pollutant. The warning level for human health on a given day is a value greater than 100, as established by CAA (Clean Air Act). Table 2. demonstrates the six levels of health alarm of AQI. 
Table 2. Six levels of health alarm of AQI

\begin{tabular}{ccc}
\hline AQI values & Levels of health concern & Colors \\
\hline $0-50$ & Good & Green \\
$51-100$ & Moderate & yellow \\
$101-150$ & Unhealthy for Sensitive Groups & Orange \\
$151-200$ & Unhealthy & Red \\
$201-300$ & Very Unhealthy & Purple \\
$301-500$ & Hazardous & maroon \\
\hline
\end{tabular}

\subsection{Aggregate AQI (AAQI)}

An AAQI, calculate the combined effects of all the pollutants. In this index, there are vast ranges of emphasis on the potential chronic health effects and long term damages on the environment caused by air pollution. The adopted formula for defining of the AAQI is as follows:

$A A Q I=\left(\sum_{i=1}^{n}\left(A Q I_{i}\right)^{p}\right)^{1 / p}$

Where AQI is the index for the single pollutant $i, p$ is a pollutant irrelevant constant in the range $[1, \infty)$. When $p=\infty$ (in an extreme condition), the AAQI equals the maximum among the single AQI of all pollutants. For $\mathrm{p}=1$ (in the other extreme condition), the index obtained AAQI corresponds to the linear summation of all AQI indices. This method is applied by US EPA, by CITEAIR. The careful selection of p is still a concern for scientists. Hu et al. (2015) [8] and Ruggieri and Plaia (2011) [1] suggested values of p between 2 and 3.

Even though we believe that $\rho$ should be selected based on the air quality [18],we do not need to consider $\rho$ level values higher than 2 since, in the considered data set pollutant concentrations to fall, at most, into the moderate class $\left(\mathrm{AQI}_{\mathrm{i}} \leqslant 70\right)$ for all pollutants. So in this study, we considered the number of 2 for $\mathrm{p}$. The AAQI was converted to the same scale of 0-500 for better comparison with AQI. In order to get a measure of variability, it can be noticed, on the one hand, that when only one pollutant occurs and all the other concentrations are zero the sum and the maximum happens at the same time; in this case AAQI1-AAQI $\infty=0$. On the other hand, when the concentrations of all the pollutants are maximum, AAQI1-AAQI $\infty=$ maximum. So, an index of variability among pollutant concentrations could be defined as $\mathrm{V}=\mathrm{AAQI1}-\mathrm{AAQI} \infty$. In fact, $\mathrm{V}$ could present a drawback; it could assume the same value with two completely different scenarios. The difference VN= NAAQI1-NAAQI $\infty$ overcomes such problems, where:

${ }_{N} I_{p}=\frac{I_{p}}{\max \left(I_{p}\right)} 100$

If all pollutants have the highest variability, an index of relative variability can be defined as:

$V_{R}=\frac{V_{N}}{\max V_{N}}=\frac{V_{N}}{80}$

With $0 \leqslant V_{R} \leqslant 1$. Obviously, $V_{R}=0$ if all the pollutants have the same concentration. It indicates whether AAQI value depends mainly on one pollutant $\left(\mathrm{V}_{\mathrm{R}}\right.$ close to 1$)$ or if it is influenced by more pollutants ( $\mathrm{V}_{\mathrm{R}}$ close to 0 ).

\section{Results and Discussion}

In spite the fact that air pollution data are complex, environmental synthetic indices can summarize complex situations in a single figure, allowing for comparisons in time and space [3]. Indices for the investigation of the air pollution situation have been advanced since the 1990s and number of different definitions of AQI can be found in numerous studies. AQIs are able to be considered as a simple and reasonable way of measuring air quality, often, but not always, with regard to its effects on human health. In Figure 2. the monthly AQI are given for each pollutant and for each year, may help to better understand. Figure 2. shows how $\mathrm{PM}_{10}$ has the highest concentrations for 2007, 2008 , and 2009. However, these concentrations were in the "moderate level", (80, 89, and 95, respectively). By recording data for PM 2.5 since 2010, we found that the emission of this pollutant is in the highest concentration. As a result, the AQI of PM 2.5 for 2010, 2011, 2012, and 2013 were 139, 123, 119, and 133, respectively which overcoming threshold value and all fall in "Unhealthy for Sensitive Groups level". While AQI for the rest of pollutants in the last 4 years have been reported less than 100. In the second step, the function AAQI is used. Based on the explanations that have already given, AAQI is 
computed for the monitoring of the data. The indicator for the years of 2007, 2008, and 2009 include only the five pollutants $\left(\mathrm{CO}, \mathrm{O}_{3}, \mathrm{NO}_{2}, \mathrm{SO}_{2}\right.$, and $\left.\mathrm{PM}_{10}\right)$, this is due to the fact that $\mathrm{PM}_{2.5}$ is not measured in these years. If just one of the five considered concentrations is missing or unreliable, AAQI is missing on that time; AAQI is a power sum and its range depends on the number of pollutants. Consequently, it is computed for a constant number of AQI, in order to give comparable variables. This problem is mentioned in Ruggieri et al [1] and was solved by imputing them before standardization.
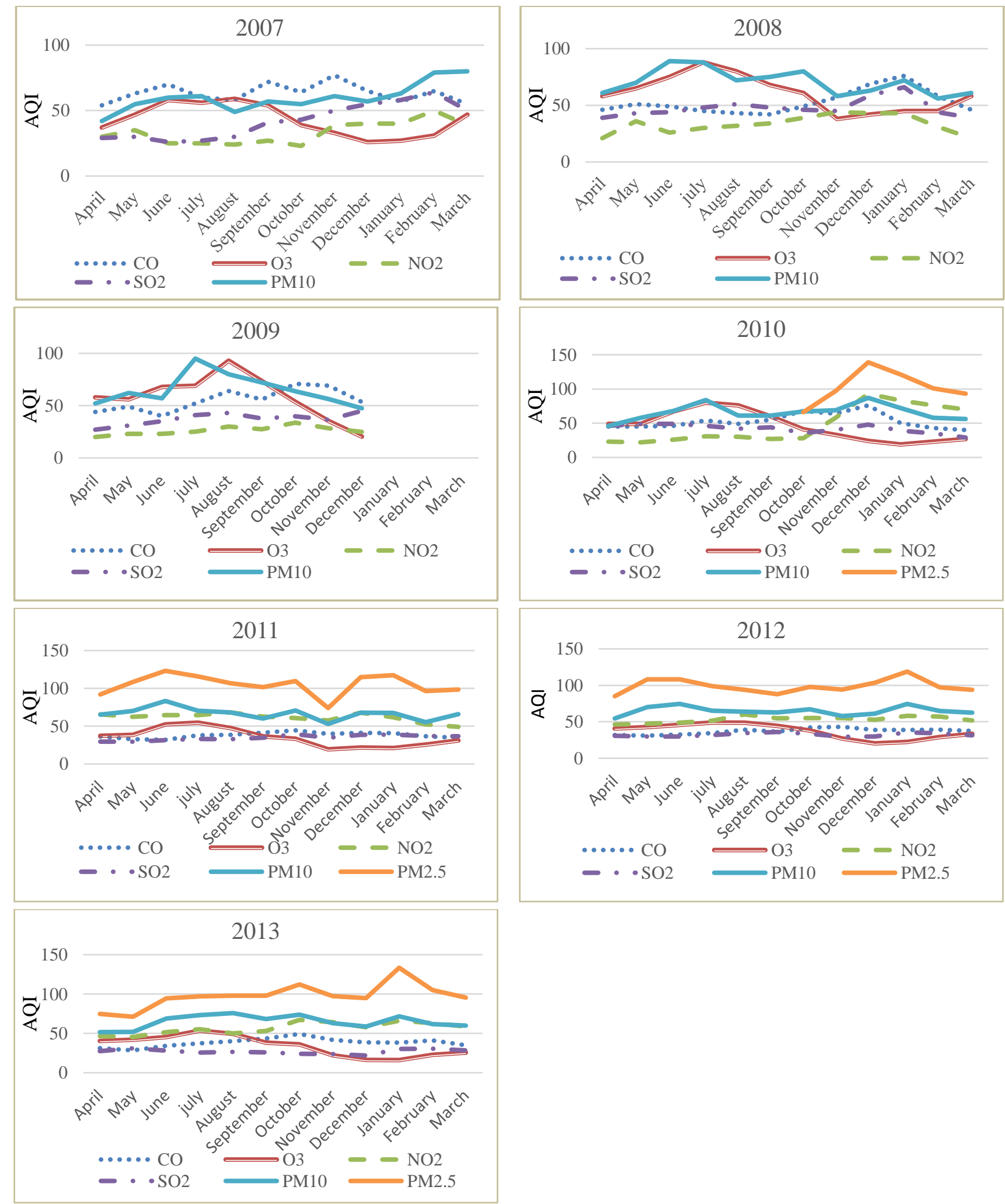

Figure 2. Pollutant concentration standardized (AQI) for each year 
In Figure 3. AQI values over the days for all the years are plotted. Information about years that are more or less polluted than others can be obtained from this graph, Figure 3. and Table 3. shows 2011 with 234 unhealthy days (218 days for $\mathrm{PM}_{2.5}, 12$ days for $\mathrm{PM}_{10}$, and 4 days for $\left.\mathrm{NO}_{2}\right)$ is the most polluted year and 2007 with 16 unhealthy days (7 days for $\mathrm{CO}$, and 9 days for $\mathrm{PM}_{10}$ ) is the least polluted. As shown in Table 4, the number of unhealthy days due to $\mathrm{CO}$ emissions is reached to zero. Because the Environmental Protection Agency in Tehran has prevented producing carburetor vehicles since 2003 and implemented policies that resulted into remove major air pollutants, such as CO, after almost a decade. This suggests that policies and programs to reduce air pollution is time-consuming but ultimately a correct policy can give rise to the correct result. By recording $\mathrm{PM}_{2.5}$ data since 2010, it was revealed that $\mathrm{PM}_{2.5} \mathrm{creates}$ the most severe problems in Tehran presenting the highest concentrations for almost all the years it often reaches concentrations greater than 100 (threshold value). The second pollutant showing higher concentrations than other pollutants is $\mathrm{PM}_{10}$; it sometimes also overcomes threshold value. These conditions are similar for the years of 2010 , 2011, 2012, and 2013.

Table 3. The number of polluted days in each year

\begin{tabular}{cccccccc}
\hline Years & $\mathbf{C O}$ & $\mathbf{O}_{\mathbf{3}}$ & $\mathbf{N O}_{\mathbf{2}}$ & $\mathbf{S O}_{\mathbf{2}}$ & $\mathbf{P M}_{\mathbf{1 0}}$ & $\mathbf{P M}_{2.5}$ & Total \\
\hline 2007 & 7 & 0 & 0 & 0 & 9 & - & 16 \\
2008 & 7 & 15 & 0 & 0 & 43 & - & 65 \\
2009 & 2 & 16 & 0 & 0 & 19 & - & 37 \\
2010 & 4 & 7 & 15 & 0 & 22 & 84 & 132 \\
2011 & 0 & 0 & 4 & 0 & 12 & 218 & 234 \\
2012 & 0 & 0 & 0 & 0 & 9 & 148 & 157 \\
2013 & 0 & 0 & 0 & 0 & 10 & 159 & 169 \\
\hline
\end{tabular}

Table 4. Population and AQI, AAQI, and $V_{R}$ for pollutants in different years (mean \pm standard deviation)

\begin{tabular}{cccccccc}
\hline Years & $\mathbf{2 0 0 7 - 2 0 0 8}$ & $\mathbf{2 0 0 8 - 2 0 0 9}$ & $\mathbf{2 0 0 9 - 2 0 1 0}$ & $\mathbf{2 0 1 0 - 2 0 1 1}$ & $\mathbf{2 0 1 1 - 2 0 1 2}$ & $\mathbf{2 0 1 2 - 2 0 1 3}$ & $\mathbf{2 0 1 3 - 2 0 1 4}$ \\
\hline Population (Million) & 7.91 & 8.02 & 8.1 & 7.98 & 8.15 & 8.31 & 8.22 \\
AQI & $67 \pm 8$ & $72 \pm 11$ & $71 \pm 14$ & $85 \pm 27$ & $105 \pm 13$ & $99 \pm 9$ & $98 \pm 16$ \\
AAQI & $113 \pm 12$ & $123 \pm 13$ & $115 \pm 19$ & $138 \pm 32$ & $152 \pm 15$ & $144 \pm 9$ & $143 \pm 17$ \\
V.100 & $24 \pm 5$ & $24 \pm 9$ & $29 \pm 9$ & $37 \pm 23$ & $60 \pm 11$ & $56 \pm 10$ & $56 \pm 15$ \\
unhealthy days & 16 & 65 & 28 & 132 & 234 & 157 & 169 \\
\hline
\end{tabular}

High concentration of the PM is directly related to traffic. One of the main reasons for the increase of the pollutant in Tehran is diesel vehicles, especially motorcycles and trucks, which are produced with low standard. To reduce the emission of PM, natural-gas vehicles are replaced with gasoline-powered vehicles. Unfortunately, the results showed that the performances of these vehicles were not according to the standard and the vehicles are far worse pollution than gasoline vehicles.

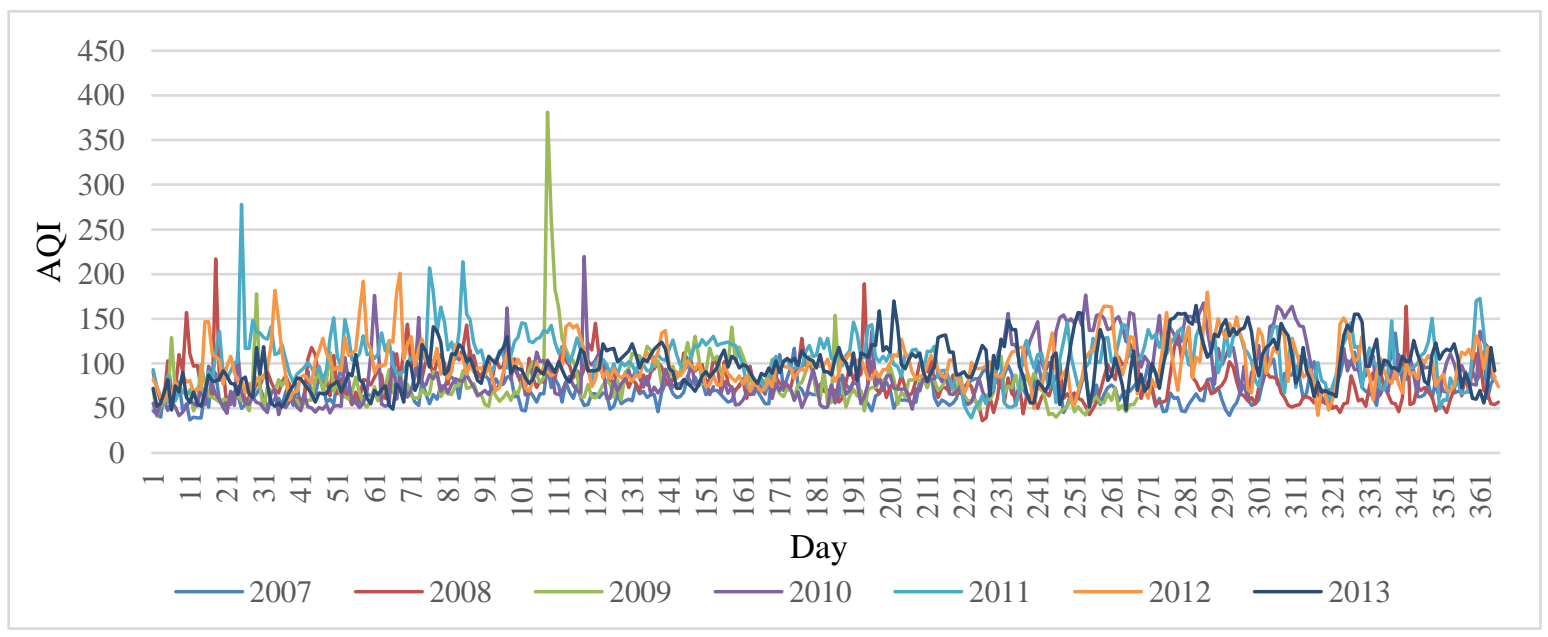

Figure 3. AQI values computed on pollutants for all years of the city of Tehran 
In Table 4, the index AQI, together with AAQI, and $V_{R}$ is computed for every year. The $V_{R} .100$ was considered instead of $\mathrm{V}_{\mathrm{R}}$ for a better understanding. $\mathrm{V}_{\mathrm{R}} .100=\mathrm{min}=24$ for the year of $2007(54,63,70,61,59,72,64,77,65,63,79$, 80 ), where similar concentration occur. For this year all concentrations fall within the "moderate class". The values of AQI and AAQI for all pollutants are calculated 67 and 113, respectively. $V_{R} .100=$ max $=60$ for the year of 2011 ( 92,108 , $123,116,107,102,110,74,115,118,96,98)$, where high variability among the 12 monthly concentrations occur. For this year, 8 concentrations fall within the "Unhealthy for Sensitive Groups" while 4 concentrations fall in the "moderate class". The values of AQI and AAQI for all pollutants are calculated 105 and 152, respectively.

In Figure 4. $V_{R}$ values for all the years are reported. In this case, only five pollutants $\left(\mathrm{CO}, \mathrm{O}_{3}, \mathrm{NO}_{2}, \mathrm{SO}_{2}\right.$, and $\left.\mathrm{PM}_{10}\right)$ have been considered for years of 2007, 2008, and 2009 because the data of $\mathrm{PM}_{2.5}$ was not recorded for the years. Since 2010, six pollutants $\left(\mathrm{CO}, \mathrm{O}_{3}, \mathrm{NO}_{2}, \mathrm{SO}_{2}, \mathrm{PM}_{10}\right.$, and $\left.\mathrm{PM}_{2.5}\right)$ were applied to calculate of AAQI and $\mathrm{V}_{\mathrm{R}}$. Figure 4. shows how the variability among pollutants tends toward the highest values for 2011. This variability depends certainly on $\mathrm{PM}_{2.5}$.

In Table 5. we considered different days and just four years that had the data of six pollutants. Because comparisons between different years are possible only if the same number of pollutants is considered for years to be compared. $V_{R}$ together with AAQI values is reported in Table 4. in order to show how $V_{R}$ may help to distinguish different situations when similar values for AAQI occur. In all considered days, AAQI is high (greater than 100). As previously mentioned, the $V_{R}$ ranges are between zero and one. If the index is zero, indicating that the concentration of all pollutants is the same. For data examined in this study, these conditions did not exist. If $V_{R}$ is close to zero, the AAQI value influenced by more pollutants. Such situations almost happened in 2010 on day $44\left(V_{R}=0.09\right)$. If $V_{R}$ is close to one, the AAQI value influenced by one pollutants. For example, in 2011 on day 159 that has AAQI=163 representing unhealthy situation and $\mathrm{V}_{\mathrm{R}}=0.76$ representing the AAQI value influenced by one pollutant $\left(\mathrm{PM}_{2.5}\right)$. In addition, if AAQI for years of 2011 and 2013 are compared on day "259", they have the same value of AAQI (175), and AAQI for these years depends mainly on $\mathrm{PM}_{2.5}$, having a higher concentration than other pollutants. But by comparing of $\mathrm{V}_{\mathrm{R}}$, presenting for 2011 a higher value (0.83) compared to $2013(0.79)$. Then $V_{R}$ is a useful index to be coupled with AAQI and gives additional information to AAQI. This kind of information is very useful especially when AAQI results high.

Table 5. AQI, AAQI, and $V_{R}$ computed for four years

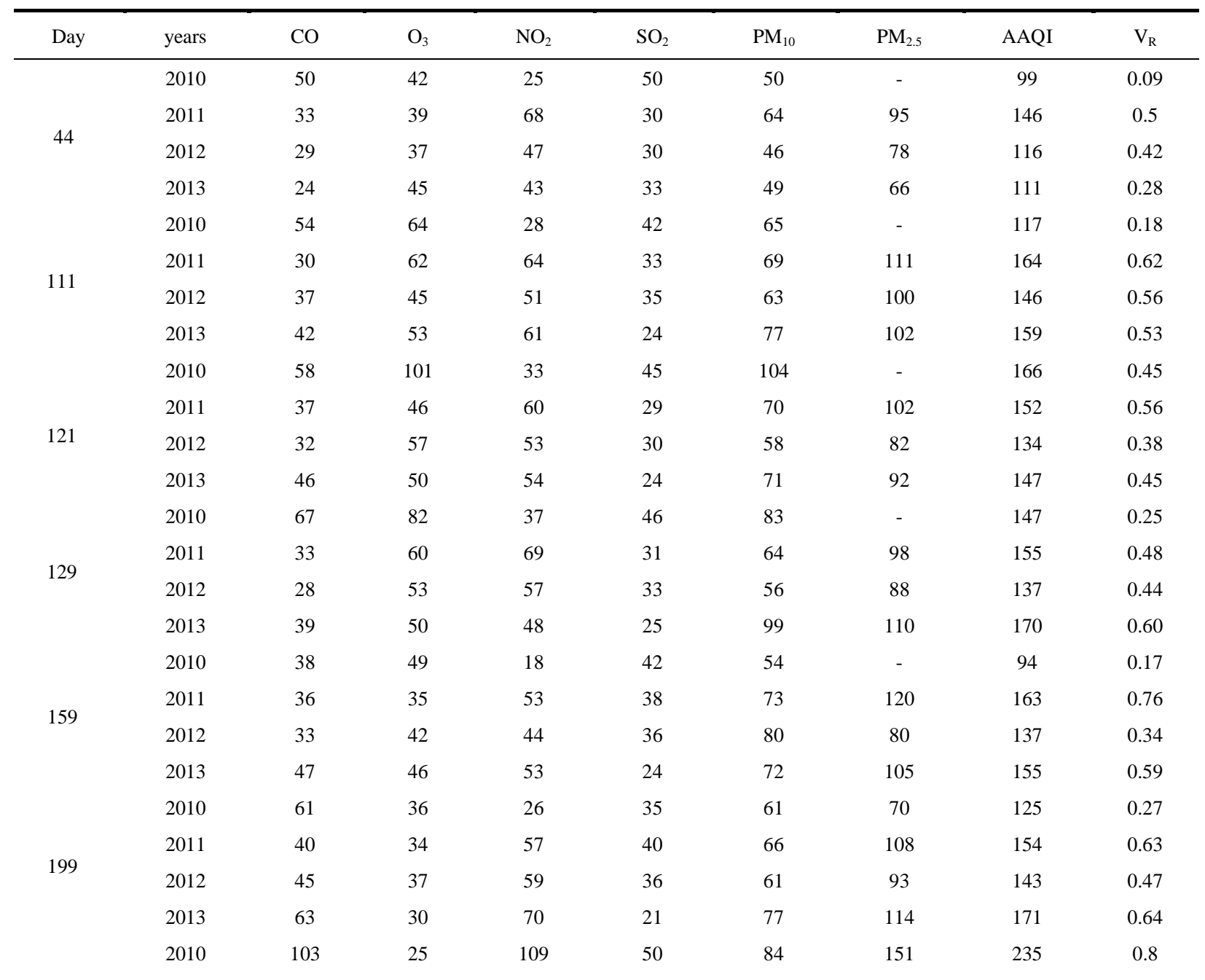




\begin{tabular}{ccccccccccc}
259 & 2011 & 39 & 18 & 68 & 41 & 78 & 128 & 175 & 0.83 \\
& 2012 & 55 & 20 & 71 & 36 & 102 & 153 & 209 & 1 \\
& 2013 & 47 & 17 & 77 & 27 & 76 & 125 & 175 & 0.79 \\
\hline
\end{tabular}
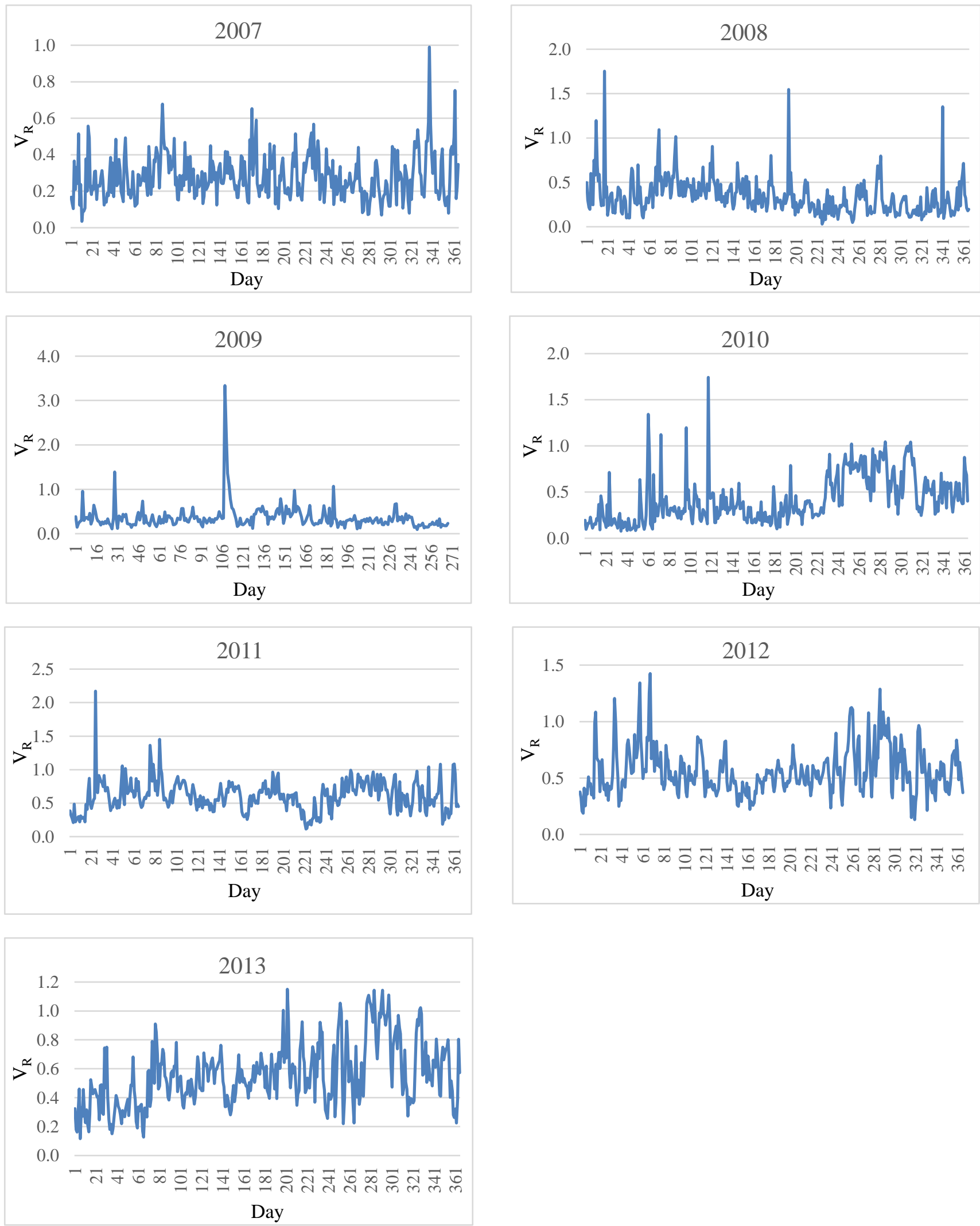

Figure 4. $V_{R}$ values computed on 5 pollutants (for 2007, 2008, and 2009) and 6 pollutants (for 2010, 2011, 2012, and 2013) of the city of Tehran 


\section{Conclusion}

All of all, any synthetic index which aims at quantifying the global air quality level depends on the quality of the standardization process used so as to make different pollutants comparable. In our study, we applied AQI, aggregate $\mathrm{AQI}$, and a variability index (VR) to indicate the combined effects of all considered. The two indices are computed together on data collected during the seven years (from March 2007 to March 2014) for the city of Tehran (Iran). We could compare different situations in time and/or space and solve forecasting issues.

The AQI of PM2.5 for 2010, 2011, 2012, and 2013 were 139, 123, 119, and 133, respectively which overcoming threshold value and all fall in "Unhealthy for Sensitive Groups level". Results also show 2011 with 234 unhealthy days (218 days for PM2.5, 12 days for PM10, and 4 days for NO2) is the most polluted year and 2007 with 16 unhealthy days (7 days for CO, and 9 days for PM10) is the least polluted.

Moreover, it was revealed that PM2.5 and PM10 create the most severe problems in Tehran presenting the highest concentrations for almost all the years it often reaches concentrations greater than 100 (threshold value). High concentration of the PM is directly related to traffic. One of the main reasons for the increase of the pollutant in Tehran is diesel vehicles, especially motorcycles and trucks, which are produced with low standard. To reduce the emission of PM, natural-gas vehicles are replaced with gasoline-powered vehicles. Unfortunately, the results showed that the performances of these vehicles were not according to the standard and the vehicles are far worse pollution than gasoline vehicles. The purpose of VR is to provide additional information about the proposed AQI, clarifying whether it is influenced by a particular pollutant or not. VR together with AAQI values is reported in order to show how VR may help to distinguish different situations when similar values for AAQI occur. So VR is a useful index to be coupled with AQI, and AAQI and gives additional information to AAQI. This kind of information is very useful especially when AAQI results high.

\section{Acknowledgment}

We would also like to show our gratitude to the Tehran air quality control organization and Tehran air pollution monitoring center for sharing their data with us.

\section{Notation}

The following symbols are used in this paper:

\begin{tabular}{|c|c|c|c|}
\hline AQI & Air quality index & AAQI & Aggregate air quality index \\
\hline HAQI & Health air quality index & $\mathrm{V}_{\mathrm{R}}$ & Relative index of variability \\
\hline $\mathrm{AQI}$ & The index of pollutant $i$ & $\mathrm{C}_{\mathrm{i}, \mathrm{m}}$ & The observed ambient concentration pollutant \\
\hline $\mathrm{i} ; \mathrm{j}$ & The health category index & $\mathrm{C}_{\mathrm{i}, \mathrm{j}}$ & $\begin{array}{l}\text { The breakpoint for the jth health categories, } \\
\text { encompass } C_{i, m}\end{array}$ \\
\hline $\mathrm{C}_{\mathrm{i}, \mathrm{j}-1}$ & $\begin{array}{l}\text { The breakpoint for the } \mathrm{j}-1 \text { th health categories, } \\
\text { encompass } \mathrm{C}_{\mathrm{i}, \mathrm{m}}\end{array}$ & $A Q I_{i, j}$ & $\begin{array}{l}\text { The AQI values of pollutant } \mathrm{i} \text { corresponding } \\
\text { to } \mathrm{C}_{\mathrm{i}, \mathrm{j}}\end{array}$ \\
\hline$A Q I_{i, j-1}$ & $\begin{array}{l}\text { The AQI values of pollutant } i \text { corresponding to } \\
C_{i, j-1}\end{array}$ & $\mathrm{p}$ & A pollutant irrelevant constant \\
\hline
\end{tabular}

\section{References}

[1] Ruggieri, Mariantonietta, and Antonella Plaia. "An aggregate AQI: comparing different standardizations and introducing a variability index." Science of the Total Environment 420 (2012): 263-272.

[2] Javed, Wasim, Anthony S. Wexler, Ghulam Murtaza, Muhammad Mazhar Iqbal, Yongjing Zhao, and Tayyaba Naz. "Chemical Characterization and Source Apportionment of Atmospheric Particles Across Multiple Sampling Locations in Faisalabad, Pakistan." CLEAN-Soil, Air, Water 44, no. 7 (2016): 753-765.

[3] Bruno, Francesca, and Daniela Cocchi. "Recovering information from synthetic air quality indices." Environmetrics 18, no. 3 (2007): 345-359.

[4] Cairncross, Eugene K., Juanette John, and Mark Zunckel. "A novel air pollution index based on the relative risk of daily mortality associated with short-term exposure to common air pollutants." Atmospheric Environment 41, no. 38 (2007): 8442-8454.

[5] Cao, Junji, Hongmei Xu, Qun Xu, Bingheng Chen, and Haidong Kan. "Fine particulate matter constituents and cardiopulmonary mortality in a heavily polluted Chinese city." Environmental health perspectives 120, no. 3 (2012): 373. 
[6] Engels, Jean Mundahl, and Paula Diehr. "Imputation of missing longitudinal data: a comparison of methods." Journal of clinical epidemiology 56, no. 10 (2003): 968-976.

[7] J. Hu, Y. Wang, Q. Ying, H. Zhang. "Spatial and temporal variability of PM 2.5 and PM 10 over the North China Plain and the Yangtze River Delta, China" Atmospheric Environment 95 (2014): 598-609.

[8] J. Hu, Q. Ying, Y. Wang, H. Zhang. "Characterizing multi-pollutant air pollution in China: comparison of three air quality indices" Environment international 84 (2015): 17-25.

[9] F. Taşpınar. "Time Series Models for Air Pollution Modelling Considering the Shift to Natural Gas in a Turkish City" CLEANSoil, Air, Water 43 (2015): 980-988.

[10] F. Shen, X. Ge, J. Hu, D. Nie, L. Tian, M. Chen. "Air pollution characteristics and health risks in Henan Province, China" Environmental Research 156 (2017): 625-634.

[11] T. Fitz-Simons. Guideline for reporting of daily air quality: Air Quality Index (AQI). Environmental Protection Agency, Office of Air Quality Planning and Standards, Research Triangle Park, NC (United States), 1999.

[12] N. Mueller, D. Rojas-Rueda, X. Basagaña, M. Cirach, T. Cole-Hunter, P. Dadvand, et al. "Health impacts related to urban and transport planning: A burden of disease assessment" Environment International 107 (2017): 243-257.

[13] B. Bishoi, A. Prakash, V. Jain. "A comparative study of air quality index based on factor analysis and US-EPA methods for an urban environment" Aerosol and Air Quality Research 9 (2009): 1-17.

[14] F. Murena. "Measuring air quality over large urban areas: development and application of an air pollution index at the urban area of Naples" Atmospheric Environment 38 (2004): 6195-6202.

[15] N. Khanna. "Measuring environmental quality: an index of pollution" Ecological Economics 35 (2000): 191-202.

[16] M. Oakes, L. Baxter, T.C. Long. "Evaluating the application of multipollutant exposure metrics in air pollution health studies" Environment international 69 (2014): 90-99.

[17] G. Kyrkilis, A. Chaloulakou, P.A. Kassomenos. "Development of an aggregate Air Quality Index for an urban Mediterranean agglomeration: Relation to potential health effects" Environment International 33 (2007): 670-676.

[18] H. Mayer, F. Kalberlah. "Two impact related air quality indices as tools to assess the daily and long-term air pollution" International Journal of Environment and Pollution 36 (2008): 19-29.

[19] F. Finazzi, E.M. Scott, A. Fassò. "A model - based framework for air quality indices and population risk evaluation, with an application to the analysis of Scottish air quality data" Journal of the Royal Statistical Society: Series C (Applied Statistics) 62 (2013): 287-308.

[20] A. Castro, N. Künzli, T. Götschi. "Health benefits of a reduction of PM10 and NO2 exposure after implementing a clean air plan in the Agglomeration Lausanne-Morges" International Journal of Hygiene and Environmental Health 220 (2017): 829-839. 